\title{
Revascularization of the Periodontium After Tooth Grafting in Monkeys
}

\author{
WALTER A. CASTELLI, CARLOS E. NASJLETI, DONALD F. HUELKE, and \\ RODRIGO DIAZ-PEREZ
}

Department of Anatomy, The University of Michigan Medical Center, Veterans Administration Hospital, Ann Arbor 48104, USA and Annapolis Hospital, Detroit, Michigan

In replanted and homotransplanted teeth a vascular network developed in the blood clot between the two parts of the torn periodontium, which allowed the grafted ligament to regain its vascularity. When dentoalveolar ankylosis developed, the periodontal vasculature was split into a number of vascular clusters. In homotransplants, a definite cellular immunologic response by the host was absent. An acrylic radicular obturator was used.

Although a number of tooth transplant studies have been reported recently, ${ }^{1-5}$ the mechanics involved in the revascularization of the periodontal membrane after replantation and homotransplantation of teeth have not been investigated thoroughly. In addition, in the past few years, there has been increased interest in clinical and experimental dental implants. The current ideas of dental implants have been formulated generally from research with heat and cold processed polymethacrylate implants. ${ }^{6-12}$

In this investigation we sought an experimental model that would permit us to observe simultaneously the membrane attached to the grafted tooth as it regains vascularity and the patterns of histologic changes induced in the membrane by an artificially placed acrylic filling in the grafted roots. The model also would permit comparison of cytologic events after replantation and homotransplantation of teeth in monkeys.

\section{Materials and Methods}

Ten adult, male Rhesus monkeys with permanent dentition were used. Intraoral

This study was supported by Faculty Research Grant 1433 from The Horace Rackham School of Graduate Studies, The University of Michigan, Ann Arbor, Mich. Received for publication April 10, 1970 . radiographs were taken initially for studying the general morphology of the incisor teeth and surrounding bony regions. At the time of surgery two monkeys were treated simultaneously. The following surgical procedures were followed in each instance: extraction of the right maxillary central incisor followed by replantation of the tooth into the same socket and extraction of the mandibular central incisor followed by its transplantation into the corresponding socket of another unrelated monkey. Hence, surgery was accomplished simultaneously where two replants and two homotransplants were performed. The left central incisors were left untreated to serve as controls.

Pentobarbital sodium (Nembutal*) 30 $\mathrm{mg} / \mathrm{kg}$ of body weight, was used as the anesthetic. After extraction of the tooth, careful root canal therapy followed. ${ }^{13}$ Care was taken to maintain the vitality of the periodontal membrane attached to the root surface. A retentive cavity was drilled into the distal surface of the root, and filled with Sevriton, $\dagger$ a self-setting acrylic. The immobilization of the replanted maxillary tooth was obtained by cementing a common metal inlay into previously prepared cavities in both right and left central incisors. The mandibular homotransplanted tooth was immobilized by using an acrylic splint that included the four mandibular incisors and canines. As an aid in the prevention and treatment of infection, the monkeys were given $100 \mathrm{mg}$ of oxytetracycline (Cosa Terramycin $)$ dissolved in 16 ounces of water daily.

* Nembutal Sodium R, $50 \mathrm{mg} / \mathrm{ml}$, Abbott Laboratories, Chicago, IIl.

† Sevriton R, Amalgamated Dental Trade Distribution, Ltd., London W.1, Eng.

\# Cosa Terramycin R, Department of Veterinary Medicine, Pfizer, Inc., New York, NY. 
Postoperative radiographs were taken. Monkeys were given a soft diet for one week after surgery.

Monkeys were killed postoperatively at 3 , 6 , and 21 days and $1,3,4$, and 6 months. The common carotid vessels were cannulated and a $50 \%$ aqueous solution of India ink was perfused into the head and neck region. The specimens were fixed in $10 \%$ buffered formalin solution, and decalcified either in formic acid, ethylenediaminetetracetic acid (EDTA), or nitric acid. Acrylic obturators were dissolved in chloroform for four hours. Each specimen containing both the experimental and control teeth was sectioned into vestibular and lingual halves. One half, used for serial histologic sections, was stained with Mallory's periodic acid-Schiff (PAS), resorsin-fucsin, or hematoxylin-eosin stains, whereas the other half was cleared according to the Spalteholtz method. ${ }^{14}$

\section{Results}

Although ten monkeys were used originally for the investigation, one of them died during operation. Therefore, the following results are based on data from nine monkeys. Of the nine replants performed, gross radiographic and histologic examination at inter- vals varying from three days to six months were made on all. Seven of the nine homotransplants were available for study. In this group, the three-month-postoperative monkey lost its tooth because of fracture during the extraction procedure, and the fourmonth-postoperative monkey lost its tooth presumably because of advanced ankylosis (Table).

Three days after surgery both replanted and homotransplanted teeth had the periodontium attached to the inner side of the alveolus separated from the cementum by an organizing blood clot. This clot intervened between the sectioned ligament and extended to the level of the dental crevice (Fig 1). The clot showed a thin fibrinous substrate with a variable amount of engulfed red blood corpuscles. At six postoperative days, perfused capillaries, well outlined by India ink, were seen on both sides of the blood clot. Periodontal fibers were viable and no apparent degenerative changes were observed. At this time, the incorporation process of the graft by the host consisted mainly of a vascular reaction that was focused preferentially around the apical region of the grafted root. The central target for this vascular invasion was the blood clot be-

TABLE

RESULTS OF EXPERIMENT

\begin{tabular}{|c|c|c|c|c|}
\hline Treatment & Period & Revascularization of Membrane & Ankylosis & Response to Acrylic \\
\hline \multirow[t]{7}{*}{ Replants } & 3 days & $\begin{array}{l}\text { Clot organization; cementum side } \\
\text { without blood capillaries }\end{array}$ & $\cdots$ & $\cdots$ \\
\hline & 6 days & $\begin{array}{l}\text { Well-outlined capillaries seen on } \\
\text { both sides of blood clot }\end{array}$ & $\cdots$ & $\cdots$ \\
\hline & $\begin{array}{l}3 \text { weeks } \\
1 \text { month }\end{array}$ & $\begin{array}{l}\text { Vascular clusters of variable sizes; } \\
\text { rearrangement of vessels }\end{array}$ & $\begin{array}{l}\text { Deposition } \\
\text { of bone }\end{array}$ & Local hyperemia \\
\hline & $\begin{array}{l}1 \text { month } \\
1 \text { month }\end{array}$ & $\begin{array}{l}\text { Rearrangement of vessels; vascu- } \\
\text { lar adaptation to ankylosis }\end{array}$ & Ankylosis & Pseudomembrane \\
\hline & 3 months & $\begin{array}{l}\text { Normal vascularity developed, ir- } \\
\text { regular near proliferation }\end{array}$ & Ankylosis & $\begin{array}{l}\text { Fibroblastic } \\
\text { proliferation }\end{array}$ \\
\hline & 4 months & Normal vascularity developed & No ankylosis & Pseudomembrane \\
\hline & 6 months & Normal vascularity developed & No ankylosis & $\begin{array}{l}\text { Chronic inflam- } \\
\text { mation }\end{array}$ \\
\hline \multirow{9}{*}{$\begin{array}{l}\text { Homo- } \\
\text { transplants }\end{array}$} & 3 days & Similar to replants of 3 days & . . & . . \\
\hline & 6 days & Similar to replants of 6 days & & ... \\
\hline & 3 weeks & $\begin{array}{l}\text { Permeability of membrane com- } \\
\text { pleted }\end{array}$ & Ankylosis & Pseudomembrane \\
\hline & 1 month & Vascular adaptation to ankylosis & Ankylosis & Pseudomembrane \\
\hline & 1 month & Vascular adaptation to ankylosis & Ankylosis & Pseudomembrane \\
\hline & 1 month & Vascular adaptation to ankylosis & Ankylosis & Pseudomembrane \\
\hline & 3 months & Tooth lost & & \\
\hline & 4 months & Tooth lost & & \\
\hline & 6 months & Irregular vascularity developed & Ankylosis & $\begin{array}{l}\text { Chronic inflam- } \\
\text { mation }\end{array}$ \\
\hline
\end{tabular}




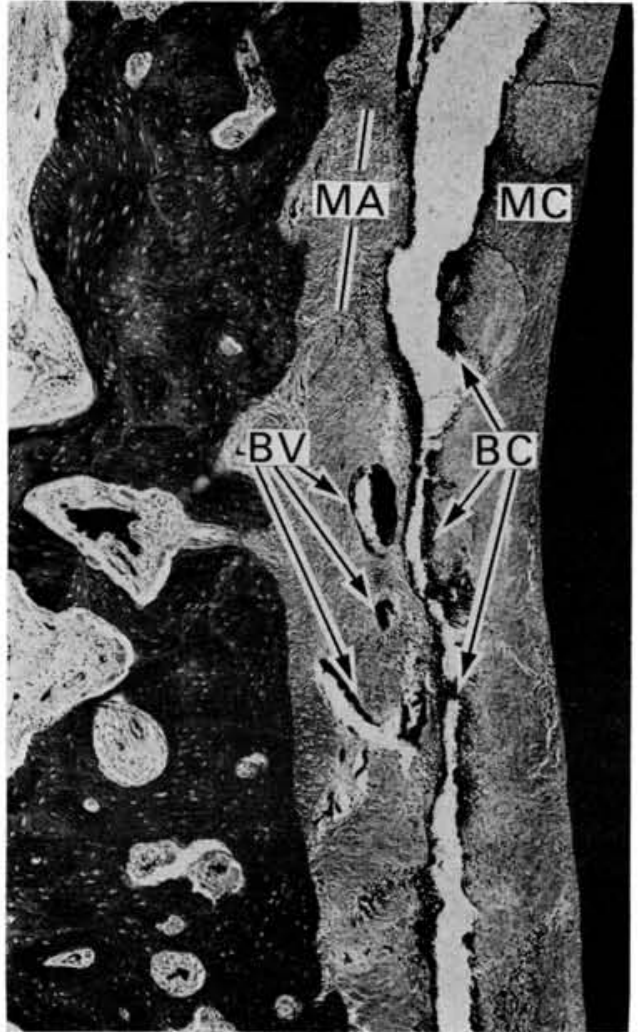

FIG 1.-Three days after replantation. General view of the periodontium shows the membrane torn into two parts, one part attached to inner side of the alveolus $(M A)$, the other, to cementum of the root $(M C)$. Blood clot $(B C)$ under organization intervenes between two parts of ligament. India ink perfused vessels $(B V)$ are present only in part of membrane attached to alveolus.

tween the two split sections of the periodontium. In the clot, the vessels formed a wide vascular network that was functionally significant for making proper vascular connections with the vessels contained in the grafted periodontium and for organizing the blood clot itself (Figs 2, 3).

Modification in the periodontal vascular patterns appeared when metaplastic changes began to develop in the fibrous connective tissue of the ligament. These changes were precocious and first appeared in the 21-postoperative-day specimens. They made possible the cytodifferentiation of connective tissue cells into osteoblasts with formation of multiple spots of bone matrix and bone spicules (Fig 4). One month after surgery,

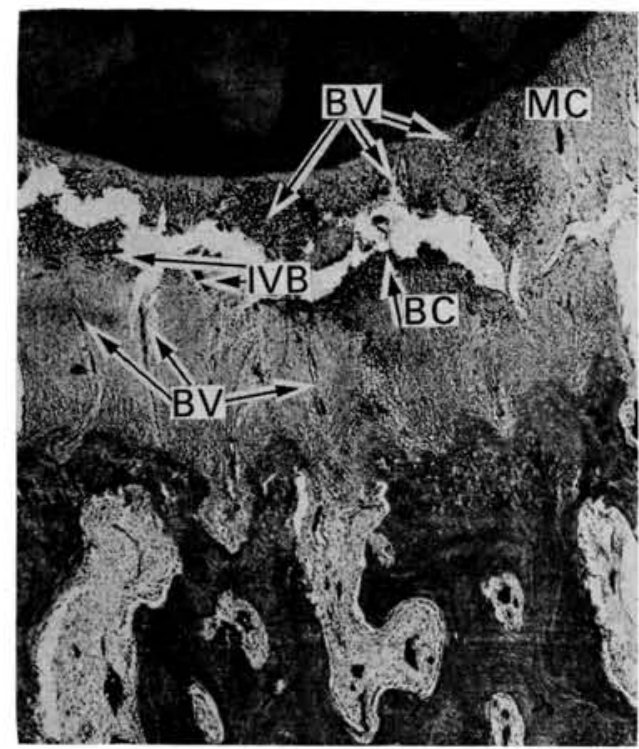

FIG 2.-Six days after replantation. Generous vascular permeability is noted in alveolar side of torn periodontium. Vessels $(B V)$ converge into an intermediate vascular bed $(I V B)$ located around blood clot $(B C)$ undergoing organization. Number of blood vessels $(B V)$ had been perfused in periodontal ligament attached to apex of root $(M C)$.

as a consequence of the dentoalveolar ankylosis, the periodontal ligament was split into a number of secondary regions, a condition that forced the periodontal vessels to rearrange themselves into vascular clusters of variable sizes that drained independent segments of the ligament (Fig 5). Specimens taken from most of the monkeys killed at 3,4 , and 6 months after surgery, showed an intense, progressive, osteogenic activity about the distal half of the root. In the periodontal space, there were multiple spots of bony ankylosis with cementum resorption and ingrowth of fibrous connective tissue in the root dentin. As a consequence of this bony ankylosis, vascular clusters disappeared and were replaced by vessels typical to those found in bone marrow spaces.

Comparative histologic study between replants and homotransplants at the onset of ankylosis showed that replants have relatively faster deposition of bone trabecules and an earlier bony bridging between root cementum and alveolar wall. The progression of ankylosis was also faster in replants than in homotransplants (compare Figs 4 and 6). Although the early healing-in of the 


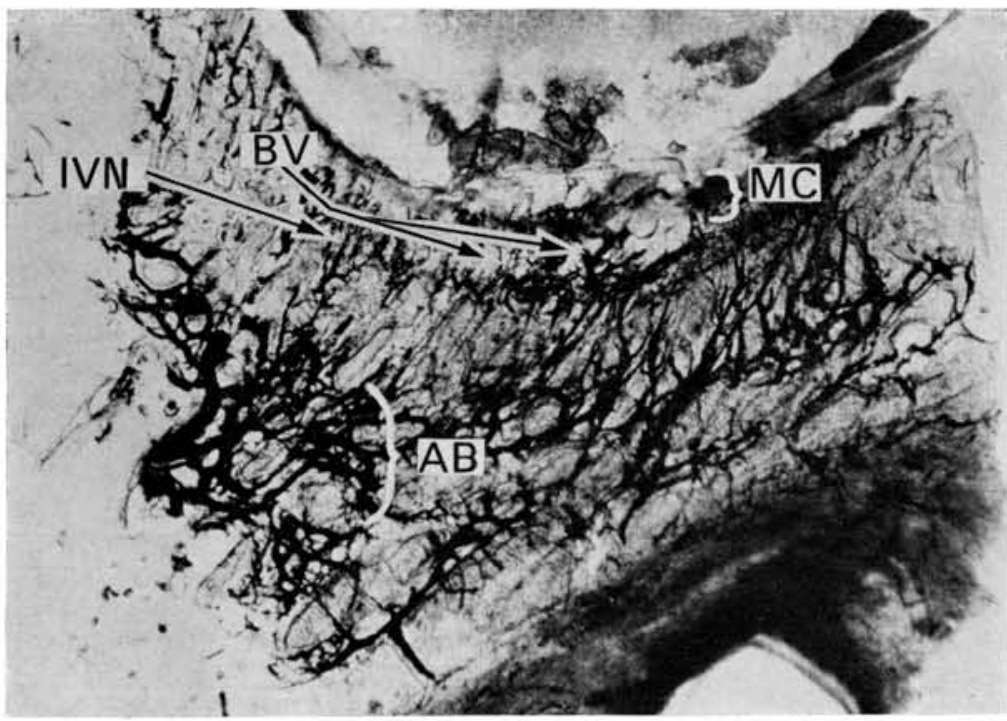

FIG 3.-Cleared preparation obtained from same specimen shown in Figure 2. From intermediate vascular network $(I V N)$ a number of blood vessels $(B V)$ penetrate the membrane attached to apex of root $(M C)$. Alveolar bone $(A B)$ shows abundant vascular supply.

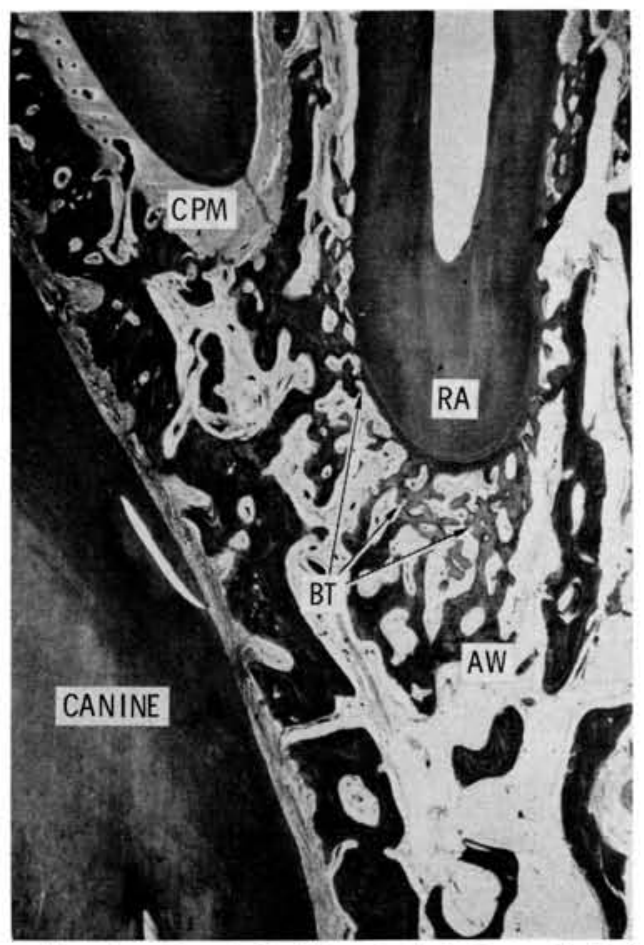

FIG 4.-Alveolodental ankylosis in replanted specimen three weeks after surgery. Fast elaboration of bony trabecules $(B T)$ was characteristic feature in replants. $R A$, root apex; $A W$, alveolar wall; $C P M$, control periodontal membrane. graft and reestablishment of the blood circulation in homotransplants was similar to that of replants, this process was not followed by a massive invasion of lymphocytes, plasma cells, and macrophages. Only a moderate number of these cells were observed in the homotransplants.

Tissue reaction occurred in the periodontal membrane adjacent to the acrylic surface. The reaction consisted of formation of a pseudomembrane of condensed fibrous tissue with just a few red blood corpuscles infiltrating the region. At other times this pseudomembrane induced a chronic inflammatory response. In one specimen from a three-postoperative-month replanted tooth a fast fibroblastic proliferation was detected in the pseudomembrane, which appeared to infiltrate the adjacent bone and dentin. The dentin surrounding the acrylic obturator appeared considerably eroded by inflammatory cells. This fibroblastic proliferation did not show evidence of malignancy, and was diagnosed as young fibroblastic proliferation with erosion of dentin and destruction of bone (Fig 7).

\section{Discussion}

Under the conditions of this study, the initial pattern of incorporation and reparative vascularization of the tooth replant was similar to those of homotransplants, both in 


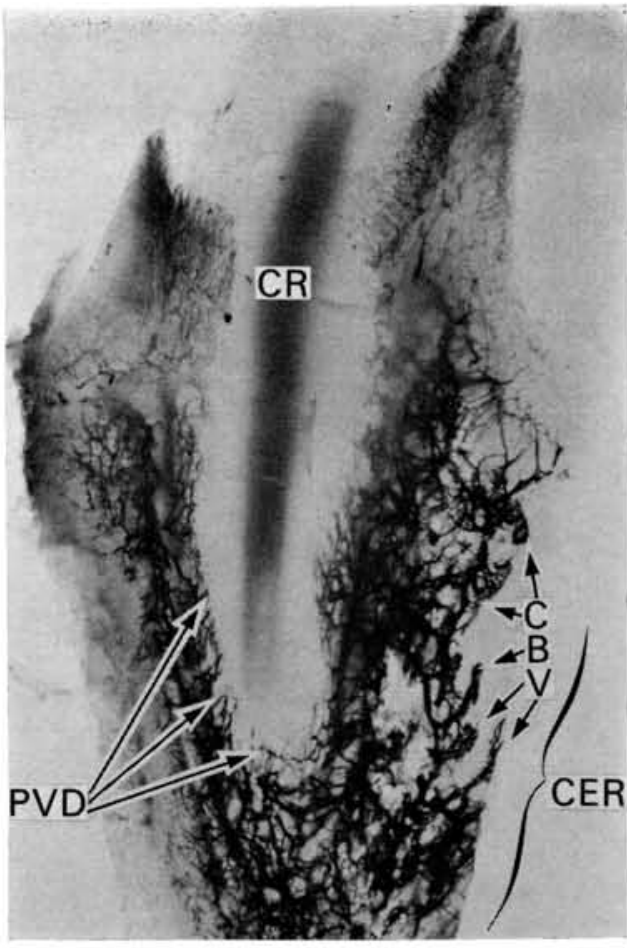

FIG 5.-One month after replantation. In this cleared specimen, the new vascular arrangement of ligament indicates adaptation to new dentoalveolar ankylosis. Isolated clusters of blood vessels $(C B V)$ are seen adjacent to cementum of experimental root $(C E R)$ and drained circumscribed areas of ligament. Normal periodontal vascular designs $(P V D)$ in control root $(C R)$.

the sequence of blood clot organization and in the establishment of vascular connections between the two parts of the torn periodontium. There was an interval between grafting and revascularization of the grafted periodontium. During this interval, the grafted ligament acquired maintenance nutrition through diffusion from host tissue fluid. In this regard, Converse, Uhlschmid, and Ballantyne ${ }^{15}$ have shown that grafted tissues gained considerable weight in the early hours after grafting and before becoming vascularized. They called this initial period "the phase of serum imbibition."

Three days after grafting, the two parts of the ligament remained separated by a rapidly organized blood clot, the main function of which was to fix the graft to the host bed and keep the graft humid. India ink perfused specimens showed vascular permeability in the grafted ligament six days after surgery, which indicates that proper vascular connections between both sections of the ligament had been accomplished previously. Castelli and Dempster, ${ }^{16}$ in studies on the topographic distribution of vessels in normal ligaments and in ligaments under experimental pressures, described the periodontal vascular complex as formed by a capillary network and some longitudinal veins contained in that part of the membrane adjacent to the cementum surface and a number of larger vessels, arterioles, and veins contained in the ligament attached to the alveolar wall. These two vascular beds were separated traumatically as a result of the extraction procedure involved in the grafting operation. Later, they were reunited when the intervening blood clot was vascularly permeable. The foregoing observations have made it clear that the traumatic interruption of the periodontal ligament circulation appear to be the common denominator in tooth grafting.

The periodontal vascular patterns were modified significantly when metaplastic changes in the fibrous connective tissue led to dentoalveolar ankylosis. This process produced segmentation of the vasculature into secondary circumscribed regions. With advanced ankylosis these vascular designs disappeared and were replaced by typical alveolar bone vessels.

The high frequency of ankylosis observed in replants and homotransplants was noteworthy. Sometimes this process was precocious. We did not expect such a response to occur, at least in the replant series. It may have been due to the response of the connective tissue to the functional changes in the dynamics of the dentoalveolar joint after surgery. These changes appeared to provoke degenerative responses in the cementum, periodontal ligament, and bone, by stimulating resorption or osteogenic proliferation. A similar pathologic reaction occurs sometimes when joints in the human body are subjected to trauma or inflammatory diseases, as indicated by Freyberg. ${ }^{17}$ The building up of bone trabecules, in the process of dentoalveolar ankylosis, also could be considered as an acceptable piece of evidence of tooth graft incorporation. Here the grafted tooth, instead of being differentiated as such, is a highly calcified tissue 


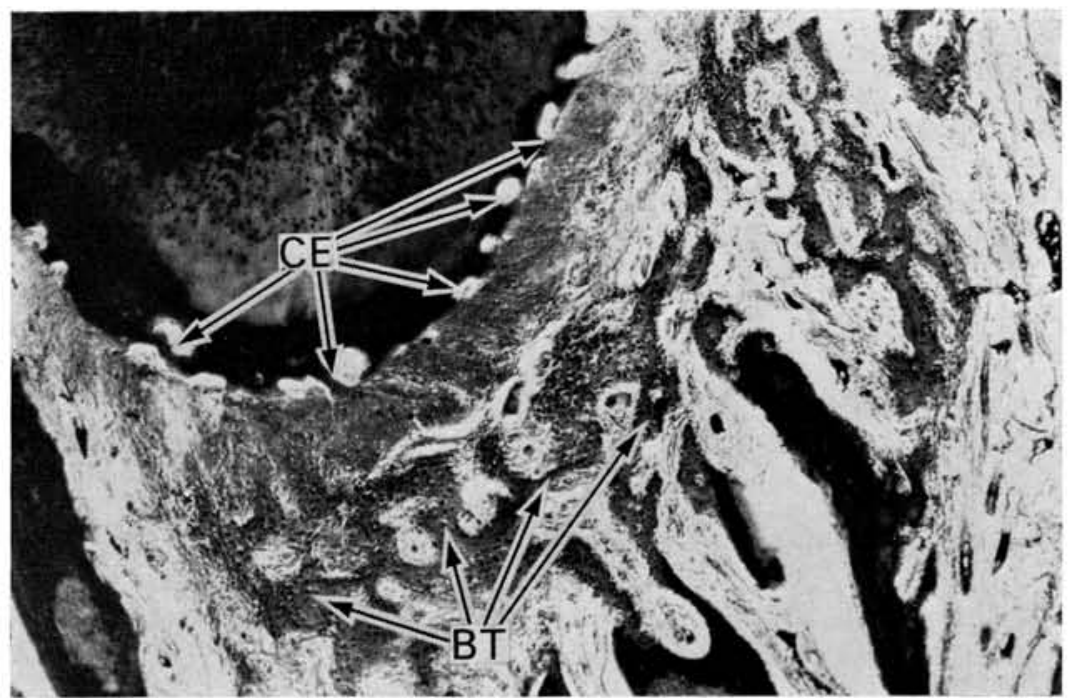

FIG 6.-Three weeks after homotransplantation. Formation of bone trabecules $(B T)$ is half way toward cementum surface. Root surface of grafted root shows multiple spots of cementum erosion $(C E)$.

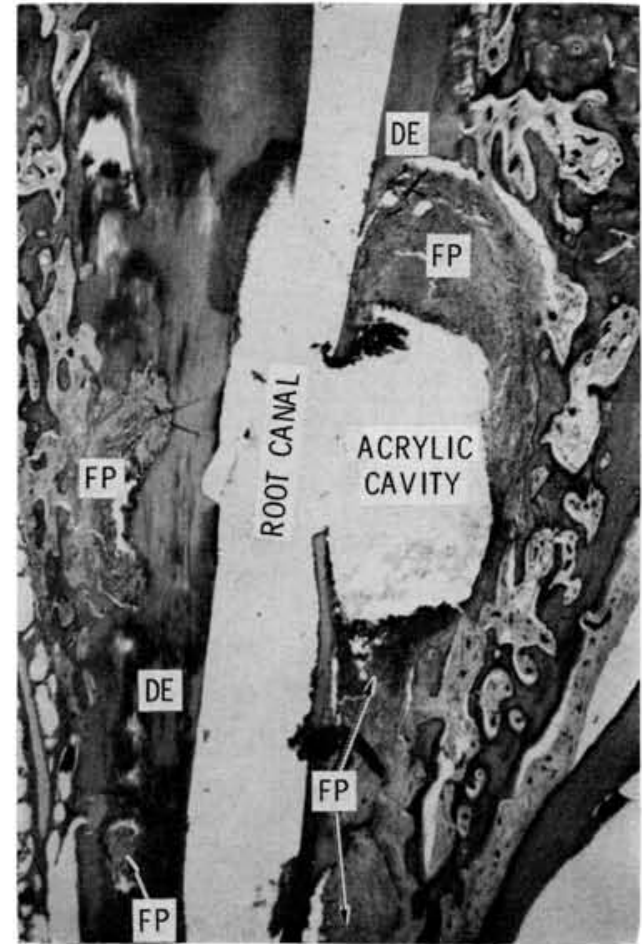

FIG 7.-Three months after replantation. Dentin $(D E)$ surrounding the area where the acrylic obturator was located appears eroded considerably by inflammatory cells and young fibroblast proliferation $(F P)$. prone to be incorporated into bone. The mechanism involved in this incorporation process as described by Pappas and Beisaw, ${ }^{18}$ appears to be comparable to those that occur in bone grafting. Dentoalveolar ankylosis was intense when the grafted root was devoid of periodontal ligament. ${ }^{4}$ The importance of maintaining the integrity of the ligament to avoid excessive resorption and ankylosis has been emphasized. ${ }^{3}$

The most intriguing observation in the histologic analysis of this study was that none of the tooth homografts were followed by massive invasion of lymphocytes, plasma cells, and macrophages - the classic histologic picture of a frank immunologic response. These cells were seen only in moderate numbers. Fong, Berger, and Morris ${ }^{1}$ found no concentrated lymphocytic infiltration in allogenic tooth transplants in monkeys. Similarly, Haley and Costich ${ }^{19}$ demonstrated that allografts of teeth in inbred hamsters did not show any increase in the number of lymphocytes. It should be noted that the experimental model used by us in the homograft series consisted of a fully developed tooth with root canal therapy. The blood cells contained in the ligament after the extraction procedure were washed out while keeping the ligament moistened with saline. Therefore, the only cell population with active antigenic 
determinants present in our experimental model were fibrocytes and endothelial cells. ${ }^{20}$ It appears that this cell population was not significant quantitatively to trigger a frank cellular immunologic response. Apparently our results are in contradiction with those of Schulman, ${ }^{21}$ and White and Rogers, ${ }^{22}$ who obtained a second-set rejection reaction of skin grafts in hosts previously immunized with fresh dental tissues. In these experiments, however, the cell population grafted was larger than that of our homograft model, and may have been a decisive factor in producing such an immunologic response.

Our results concerning the response of the periodontium to the cold-cured acrylic obturator were similar to those of Hodosh et $\mathrm{al}^{6-11}$ and Lam and Poon, ${ }^{12}$ who used heat and self-setting acrylic as the implant material. The findings coincided in the reorientation of the fibrous components of the ligament paralleling the main axis of the root and the inflammatory response, which was variable in intensity. However, in one of our specimens, the ligament adjacent to the acrylic implant responded with a fast fibroblastic proliferation that appeared to infiltrate adjacent bone and dentin. No malignancy was demonstrated. Previously, Waerhaug and $\mathrm{Löe}^{23}$ concluded that there was no basic difference in the tissue reaction to cold-cured and heat-cured acrylic implants. Lam and Poon, ${ }^{12}$ using acrylic root implants in humans, reported that the histologic study of the soft tissue attached to the acrylic root showed chronic inflammation. There was a massive round cell infiltration and numerous giant cells of the foreign body reaction type. No signs of malignancy were observed.

In previous studies, however, Stinson ${ }^{24}$ has reported the induction of malignant changes produced by acrylic implants in tissues of rats and guinea pigs. Likewise, Oppenheimer et al, ${ }^{25}$ using acrylic also, have demonstrated fibroblastic proliferation in rats, which frequently led to malignant changes. Furthermore the existence of cancer hazards to man from water soluble and insoluble polymers have been pointed out by Hueper. ${ }^{26}$

\section{Conclusions}

A reproducible experimental model was devised to study, in monkeys, revasculari- zation of the periodontium after replantation and homotransplantation of teeth and changes induced in the periodontal membrane by an acrylic radicular filling. In replanted and homotransplanted teeth, the grafted periodontium regained its vascularity by means of a vascular network that developed in the blood clot formed between the two parts of the torn ligament. When dentoalveolar ankylosis developed, the periodontal vasculature was split into a number of vascular clusters. In homotransplants the expected cellular immunologic response by the host, represented by a massive invasion of small lymphocytes and plasma cells, was absent. With one exception, the periodontium adjacent to the acrylic material reacted with the formation of a pseudomembrane.

\section{References}

1. Fong, Ch.; Berger, J.; and Morris, M.: Experimental Allogenic Tooth Transplantation in the Rhesus Monkey, $J$ Dent Res 47: 351-357, 1968.

2. Mazem, H.A.: An Aid in Successful Replantations and Post Resection Canal Filling Technique, Alpha Omegan 44:117-126, 1950.

3. Healey, H.J.: Reimplantation: A Brief Review and a Report of a Case Sequel, Oral Surg 6:775-779, 1953.

4. HAMMER, H.: Replantation and Implantation of Teeth, Int Dent J 5:439-457, 1955.

5. Deeb, E.; Prietto, P.; and McKenna, R.: Reimplantation of Luxated Teeth in $\mathrm{Hu}$ mans, J $S$ Calif State Dent Assn 33:194206, 1965.

6. Hodosh, M.; Montagna, W.; Povar, M.; and SHKLAR, G.: Implants of Acrylic Teeth in Human Beings and Experimental Animals, Oral Surg 18:569-579, 1964.

7. Hodosh, M.; Povar, M.; and ShKLar, G.: Periodontal Tissue Acceptance of Plastic Tooth Implants in Primates, JADA 70:362371, 1965.

8. Shklar, G.; Hodosh, M.; and Povar, M.: Tissue Reaction to the Plastic Tooth Implant, Oral Surg 22:349-351, 1966.

9. Hodosh, M.; Povar, M.; and Shklar, G.: Plastic Tooth Implants With Root Channels and Osseous Bridges, Oral Surg 24:831-836, 1967.

10. Hodosh, M.; Povar, M.; and ShklaR, G.: The Anatomic and Organic Bone Polymethacrylate Endosteal Dental Implant, Oral Surg 25:883-888, 1968.

11. Hodosh, M.; Povar, M.; and ShkLaR, G.: Experimental Findings on New Bone For- 
mation After Rat Skull Implants of Polymethacrylate and Inorganic Bone, Plast Reconstr Surg 44:582-587, 1969.

12. LAM, R.V., and Poon, K.Y.: Acrylic Resin Root Implants: A Preliminary Report, $J$ Prosth Dent 19:506, 1968.

13. Grossman, L.I., and Chacker, F.M.: Clinical Evaluation and Histologic Study of Intentionally Replanted Teeth, in GrossMAN, L.I. (ed): Transactions of The Fourth International Conference on Endodontics, Philadelphia: University of Pennsylvania Press, 1968, p 127.

14. Spalteholtz, W.: Die Arterien der Herzwand, Leipzig: S. Hirzel, 1924.

15. Converse, J.M.; Uhlschmid, G.K.; and Ballantyne, D.L.: Plasmatic Circulation in Skin Grafts-The Phase of Serum Imbibition, Plast Reconstr Surg 43:495-499, 1969.

16. Castelli, W.A., and Dempster, W.T.: The Periodontal Vasculature and its Responses to Experimental Pressures, JADA 70:890$905,1965$.

17. Freyberg, R.H.: The Joints in Pathologic Physiology, in Sodeman, W.A. (ed): Mechanisms of Disease, Philadelphia: W.B. Saunders Co., 1967, pp 935-957.

18. Pappas, A.M., and Beisaw, N.E.: Bone Transplantation: Correlation of Physical and Histological Aspects of Graft Incorporation, Clin Orthop 61:79-91, 1968.
19. Haley, E.W., and Costich, E.R.: Lymph Node Response to Allografts of Teeth, $J$ Dent Res 46:628, 1967.

20. Bevelander, G., and Nakahara, H.: The Fine Structure of the Human Peridental Ligament, Anat Rec 162:313-325, 1968.

21. Schulman, L.B.: The Transplantation of Tooth Homografts, J Oral Surg 17:389-394, 1964.

22. White, E., and Rogers, T.E.: Effects of Primary Allogenic Tooth Transplants on Rejection of Skin Allografts in Rabbits, $J$ Dent Res 46:565-570, 1967.

23. Waerhaug, J., and LöE, H.: Tissue Reaction to Self-Curing Acrylic Resin Implants, Dent Prac (Bristol) 8:234-240, 1958.

24. Stinson, N.E.: The Tissue Reaction Induced in Rats and Guinea Pigs by Polymethylmethacrylate (Acrylic) and Stainless Steel, Brit J Exp Path 45:21-29, 1964.

25. OPPENheIMER, B.S.; OPPENHEIMER, E.T.; Stout, A.P.; Willhite, M.; and DanISHEFSKY, I.: The Latent Period in Carcinogenesis by Plastics in Rats and Its Relation to the Presarcomatous Stage, Cancer 11: 204-213, 1958.

26. Hueper, W.C.: Carcinogenic Studies on Water Soluble and Insoluble Macromolecules, Arch Path (Chicago) 67:589-617, 1959. 